\title{
Assessing Studio-based Learning in a Material/Energy Balance Classes
}

\section{Dr. Richard L. Zollars, Washington State University}

Richard Zollars has been on the faculty at Washington State University for 36 years. He has had numerous educational grants, including two in support of an on-going investigation of the use of studio-based learning techniques in regular classroom settings.

Dr. Christopher Hundhausen, School of Electrical Engineering and Computer Science, Washington State University

Christopher Hundhausen is an associate professor in the School of Electrical Engineering and Computer Science at Washington State University, where he directs the Human-centered Environments for Learning and Programming (HELP) Lab (http://helplab.org). Recipient of over $\$ 2.5$ million in funding from the National Science Foundation, Dr. Hundhausen applies the methods of human-computer interaction to the design and empirical evaluation of software and pedagogies to improve learning and retention in computing and engineering education.

\section{Dr. Derrick Wayne Smith, University of Alabama in Huntsville}

Dr. Derrick Smith is an Associate Professor at the University of Alabama in Huntsville College of Education, Department of Curriculum and Instruction. He has over 14 years of professional teaching and research experience within education. His research focuses on STEM education with a primary emphasis on students with visual impairments. He is highly interested in innovative pedagogies and technologies for STEM learning at all academic levels.

Mr. Adam Scott Carter, Washington State University 


\section{Assessing Studio-based Learning in Material/Energy Balance Classes}

In a studio-based learning environment, students learn not just by doing but also by providing critiques of other student's work as well as receiving critiques on their work from other students. Studio-Based Learning (SBL) techniques have been used in variety of disciplines, most notably in architecture and fine arts. Engineering students often do this in informal settings (e.g., study groups) but rarely do so in a formal classroom setting. The critiquing activity is the strength of the learning activities in studio-based learning as it requires students to be actively engaged and encouraging with other students as they explain (teach) the material. This exercise in teaching and explaining the materials thus strengthens their understanding of the concepts. The critiquing activity also exercises higher levels of learning, as defined by Bloom's taxonomy, requiring not only factual knowledge but conceptual, procedural, and metacognitive knowledge. ${ }^{1}$

Over the past three years, we have incorporated SBL into the material/energy balance class at Washington State University. Using the SBL approach, students work three problems, starting with a simple material balance problem and finishing with a material balance problem involving a chemical reaction and a recycle stream. Historical data from the class shows that the SBL approach has dramatically reduced the percentage of students who do not successfully complete this class.

We are now assessing whether the student's analytic skills show improvement via the use of SBL. To do this, we have developed a rubric for analyzing the on-line discussions involving the students that are a part of the SBL approach. The details of the analytic approach, and the results from the past three years of SBL activities, will be presented.

\section{Studio-Based Learning}

Studio-based learning (SBL) techniques have been used in a variety of disciplines, most notably in architectural education. ${ }^{2}$ The technique is rooted in a type of constructivist learning theory called sociocultural constructivism. ${ }^{3}$ The SBL approach typically encompasses four key steps (see Figure 1). ${ }^{4}$ First, students are given meaningful problems for which they have to construct

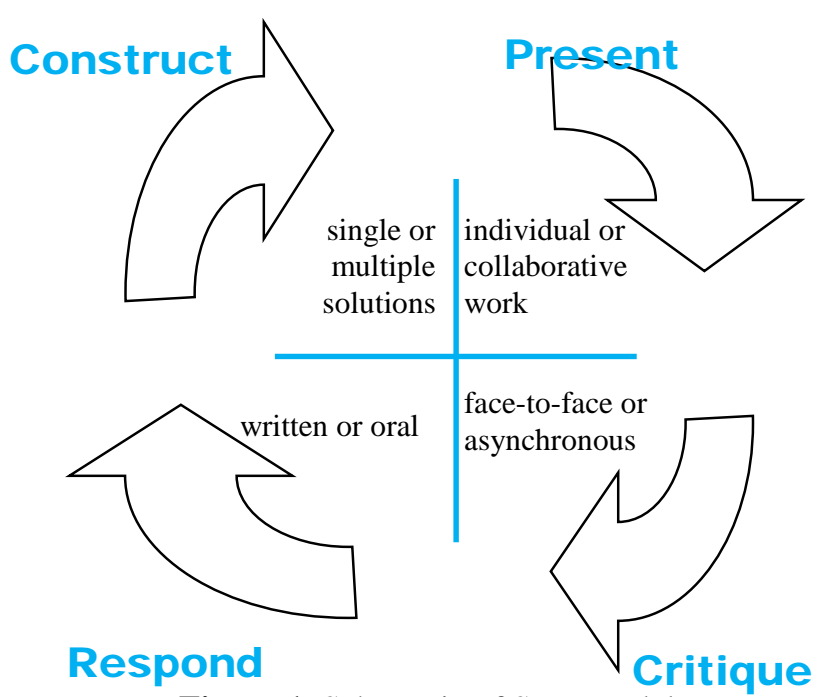

Figure 1. Schematic of SBL Model solutions. Second, students present their solutions to the entire class for discussion and feedback. Third, students' peers critique their solutions and provide comments. Finally, students are given the opportunity to respond to these comments and criticisms, and to modify their solutions appropriately.

Note that SBL, as defined above, differs from a variety of other instructional techniques that also use the terminology "studio". Among the more notable is the Scale-Up ${ }^{5}$ program introduced at North Carolina State University. In Scale-Up programs students experience a mixture of presentations, desktop experiments, web-based 
assignments and collaborative exercises while working in small groups using networked laptops (studio labs). Others have recently reported on a similar approach in chemical engineering where an active learning studio session is integrated with a more traditional lecture portion of a class $^{6}$. These approaches require active participation by the student as well as providing an open-ended problem-solving environment. However, while the critiquing and response aspect of SBL may take place in these approaches, they are not required components of the approach.

SBL is clearly an "active” learning technique. As has been cited by many authors, and summarized by Prince, ${ }^{7}$ active learning provides a much fuller educational experience. In addition to the several advantages of being an active learning technique, SBL also addresses all six cognitive levels of Bloom's taxonomy. ${ }^{8}$ Of particular importance is the critique phase of SBL wherein the Evaluation (Evaluate) level of the taxonomy is clearly invoked. This aspect of learning is not incorporated in many active learning procedures, but is an essential part of SBL.

A drawback to the implementation of SBL in a traditional class is that it is time-intensive. As the title suggests, this technique has most frequently been used in studio-based classes. The class time allotted for studio sessions is more typical of that for a laboratory class in engineering - two to three hours. So while the SBL approach might work in a class for which an extended recitation section is part of the class, the time constraints inherent in a typical one-hour lecturebased engineering class would seem to be a large impediment to using SBL. With the advent of asynchronous communication media, this no longer need be a barrier.

\section{Prior Work}

The desire to seek improvements in teaching strategies in material/energy balance classes started with the observation that approximately 35\% of the students enrolling in such classes either dropped out of the class, failed the class or received a grade lower than a " $\mathrm{C}$ " (a necessity to continue taking classes in chemical engineering at this university). This statistic seemed to be constant no matter who taught the course and also appeared to be common at other universities.

In 2007, the lead author (RZ) taught the material/energy balance for the first time. Knowing the retention rates from prior years, he sought a new strategy for teaching the class. This started by observing pairs of students solve a typical class problem. During these observations it was noted that students struggled with two major problems - translating the written problem descriptions into an appropriate graphical representation (process flow diagram), and subsequently translating the information from the diagram into mathematical expressions. ${ }^{9}$ The difficulty in obtaining important information from a verbal description is in line with the observation by Felder and Silverman that the majority of engineering students have a preference for a visual rather than a verbal learning style. ${ }^{10}$

This observation led to the development of a software tool (ChemProV) designed to provide a scaffolded environment to help the students through these two translations. In creating ChemProV, we wanted to aid the students in building their own skills in transforming written information into visual form, without giving them so much aid that the software becomes a crutch. Grounded in the learning theory of Vtogsky, ${ }^{11}$ this approach resonates with a rich legacy of software scaffolding approaches ${ }^{12,13}$ in which learners are initially aided by modifications to 
problems that make them initially more doable; the modifications are then gradually removed as learners gain more skills. ChemProV would, in addition, give students an opportunity for early success in the material/energy balance class, leading to enhanced learning according to selfefficacy theory. ${ }^{14}$

In 2008 and 2009, a laboratory experiment was conducted to assess the effectiveness of ChemProV. These results demonstrated that ChemProV provided a learning environment in which students could learn the skills needed to successfully solve material/energy balance problems. In addition, these skills remained with the students in situations where no feedback was being provided. ${ }^{15}$

Incorporating SBL into Material/Energy Balance Classes

While the results described above were encouraging, the development of ChemProV also opened the opportunity for overcoming the difficulties of using SBL in a traditional class setting. In 2011, an empirical study was conducted using ChemProV in a studio-based learning environment. ChemProV plays an important role in implementing the SBL approach by providing a common tool and format both for solving material and energy balance problems, and for presenting solutions to peers and instructors for feedback and discussion. This made it easier for the groups to understand what the problem solver was trying to accomplish and thus easier to offer suggestions about how to solve the problem. If the problem solver was stuck, groups could correct any errors in the solution that was presented, or suggest alternatives to the solution offered. Attitudinal surveys indicated that the students liked the SBL format and felt they had learned from the experience.

In order to make it possible to implement SBL asynchronously and online, we have integrated ChemProV with OSBLE, an online learning management environment developed in prior research. ${ }^{16}$ To help test the impact of SBL implemented using the ChemProV/OSBLE combination, a number of other universities (Manhattan College, North Carolina State University, Oklahoma State University, Worcester Polytechnic Institute, and the University of New Mexico) agreed to participate in a multi-year quasi-experimental study. At these schools, the participating faculty agreed to teach their material/energy balance class in their normal fashion during the 2012-2013 academic year. This would be followed by using a SBL approach, implementing ChemProV/OSBLE, during the 2013 - 2014 academic year. At Washington State University, however, the material/energy balance class was taught in its normal fashion during the 2011 - 2012 academic year and using a SBL approach in both the 2012 - 2013 and 2013 2014 academic years.

The implementation of the SBL approach in the material/energy balance class was performed in the following fashion. In the sixth week of the semester, just after the students had begun to be exposed to solving material balance problems with no chemical reactions or recycle streams, we conducted an SBL training activity in class. In this training activity, students were given a solution to the following problem.

An air stream, containing $10.0 \mathrm{wt} \%$ acetone and $90.0 \mathrm{wt} \%$ air, enters a scrubber at a total flow rate of $1.00 \times 10^{3} \mathrm{lb} / \mathrm{min}$. In the scrubber this stream is mixed with a water stream. The water 
stream entering the scrubbing unit consists of a fresh water feed and a recycled water stream coming from another unit (to be described later). Two streams leave this scrubbing unit; a liquid stream containing only water and acetone and a gas stream containing air, water and acetone. The gas stream leaving the scrubbing unit is discharged to the air. This gas stream contains $1.60 \mathrm{wt} \%$ water. The liquid stream leaving the scrubbing unit is sent to a second unit where it is heated to produce a gas stream and a liquid stream. The gas stream leaving the heater contains only acetone. It also contains $99.0 \%$ of the acetone that enters the system. The liquid stream from the heater is recycled and is mixed with the fresh water to form the water feed entering the scrubber.

Find the unknown values for all streams.

The solution contained a number of intentional errors. Attached to the solution was a small packet of Post-it ${ }^{\circledR}$ notes in one of four different colors. The students were given ten minutes to examine the solution, find areas where they disagreed with the solution, write on a Post-it ${ }^{\circledR}$ where they disagreed with solution, what the disagreement was, and how to change the solution to resolve the disagreement. Each place where they found a disagreement was to be noted on a separate Post-it ${ }^{\circledR}$.

During this time large Post-it ${ }^{\circledR}$ posters containing the same solution that had been distributed to the students were posted around the classroom. Students then were instructed to assemble in groups of four in front of these large Post-it ${ }^{\circledR}$ solution posters, with each student in the group utilizing a different color packet of small Post-it ${ }^{\circledR}$ notes. They then stuck their individual comments on the large solution at the appropriate place. With all of the students' comments on the large Post-it ${ }^{\circledR}$ poster, it was now easy to see where there was agreement amongst the students about problems with the solution as well as places where the students disagreed, as shown in Figure 2. This was followed by a 15-minute period during which the students were to discuss

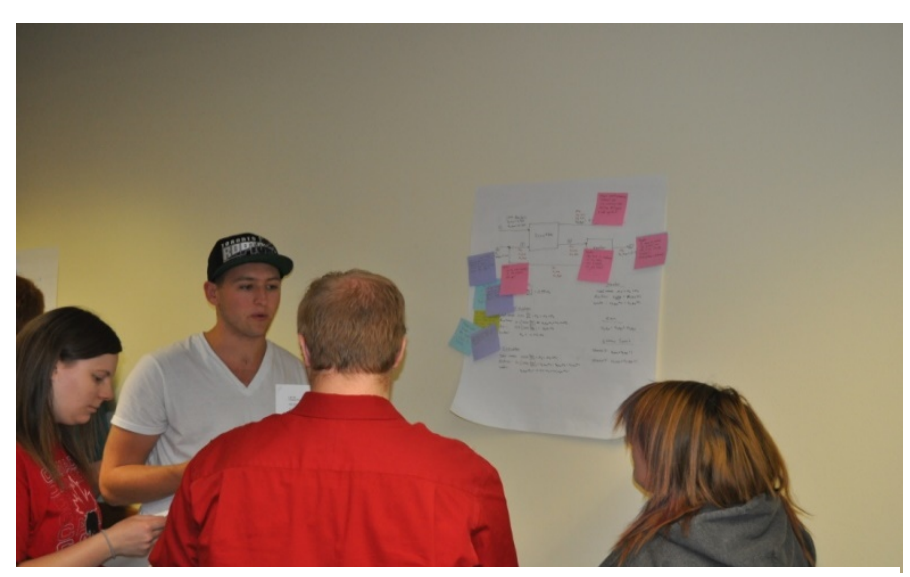

places where they were in agreement about a problem with the posted solution as well as places where there was not agreement. The consensus of these discussions was noted by one of the students in the group (a scribe selected on the basis of the color of the Post-it ${ }^{\circledR}$ note they had used). These consensus statements were recorded on a white Post-it ${ }^{\circledR}$ note and attached to the large solution at the appropriate place.

Figure 2: Students Involved in Studio-Based Learning Training Activity

Once the students had been exposed to the SBL approach in this manner, three ChemProV/OSBLE assignments were assigned during the semester. The first of these involved a material balance problem with no recycle and no energy balance. The second involved a material balance problem with recycle but no energy balance. The final problem involved both material and energy balances for a system involving a recycle stream. All of the students solved the assignment using ChemProV and 
submitted it through OSBLE. For all of the assignments a "solution" consisted of a complete process flow diagram, a degree-of-freedom analysis, and enough independent equations so the numerical values could be found for all unknowns. For each ChemProV/OSBLE SBL assignment, one-third of the initial student submissions were randomly selected for review, making sure that no student had more than one of their problem solutions reviewed during the course of the semester. Groups of three students then were assigned to review the solutions that had been selected. The identity of the student submitting the solution, as well as all members of each review group, was kept anonymous. The members of the review groups were also randomized so that the same groups were not commenting on all three solutions. The students used the electronic Post-it ${ }^{\circledR}$ note functionality in ChemProV to make their comments, just as they had with an actual Post-it ${ }^{\circledR}$ notes during the class. Once a student had submitted their electronic comments, they could then see the comments of others within their review group. Using the online discussion facilities of OSBLE, each member of the review group then could comment on areas of agreement and disagreement among the comments submitted by all review group members. Unlike the classroom activity, the asynchronous nature of OSBLE allowed the students to add to the discussion at any time rather than being confined to the class period. After one week, the students were instructed to come to a consensus and the review discussion was closed.

In order to encourage a full discussion, the teaching assistants (TAs) for the class were assigned the role of a moderator. As moderators, the TAs were encouraged to review the students' comments and encourage pursuit of relevant topic threads without providing evaluative comments. To be effective as moderators, the TAs were provided with a training manual and a short training exercise prior to their participation.

Evaluation Procedure

Evaluation of the impact of SBL on instruction in the material/energy balance class is proceeding as follows. At the start of the semester, the participating faculty gave both a problem in a standard format, and a critiquing problem (similar to that shown above) to the students in the class. The level of the problems was selected from among three levels, to be commensurate with the expectations of what the students should know by the end of that class (e.g., material balances only or both material and energy balances). At the end of the semester, the students were given the same two problems again. Scoring rubrics have been developed for all problems so that the pre- and post-class problem results could be compared to determine how much the students learned. The amount of change from the first academic year of the study (normal teaching strategy - the Control Treatment) was then compared with the change from the second academic year (OSBLE/ChemProV - the Experimental Treatment). In this paper, we report the results from Washington State Univesity, at which three years of data were collected; thus, we consider three treatments: Year 1 - Control, Year 2 - Experimental, and Year 3 - Experimental.

In addition to these results, students were also asked to complete attitudinal surveys at both the start and the end of the class. To measure attitudinal changes, we used modified forms of the Motivated Strategies for Learning Questionnaire (MSLQ) ${ }^{17}$ coupled with the Classroom Community Scale (CCS) ${ }^{18}$. Among the topics surveyed were Task Value (e.g., "I think I will be able to use what I learn in this course in other courses"), Self-Efficacy (e.g., "I'm confident I can 
understand the basic concepts taught in this course”), Critical Thinking (e.g., "I treat the course material as a starting point and try to develop my own ideas about it”), Peer Learning (e.g., "When studying for this course, I often try to explain the material to a classmate or friend"), Intrinsic Goal Orientation (e.g., "In a class like this, I prefer course material that really challenges me so I can learn new things”), Mastery Goal Orientation (e.g., "I like school work that I'll learn from even if I make a lot of mistakes”), Classroom Connectedness (e.g., "I feel connected to others in this course") and Classroom Learning (e.g., "I feel that I am encouraged to ask questions”).

Finally, students were asked to respond to the following question "After taking this course, how likely are you to continue pursuing a degree in Chemical Engineering?” using a 5-point Likert scale. Their responses to this question were used as an indicator of their Persistence in the major

The results of these surveys were combined with the comparison of pre- and post-class problem results described above, as well as data from the class (average grade, percent retention, etc.), to assess the impact of the SBL approach. This data was collected from all of the participating programs, yet only the results from Washington State University are reported here. Should significant differences in the results appear from the other programs, the results can be analyzed on a program-by-program basis rather than being pooled.

The scoring rubric for the regularly formatted problems breaks the scoring into three areas: construction of the process flow diagram, specification of stream components and quantities, and development of the balance equations. Scoring of the critiquing problems was a "yes" (they did identify the error included in the problem) or "no" (they did not) decision with the score being the number of “yes's”. The calibration for both was accomplished during face-to-face workshops, by giving the participants sample solutions to pre- and post-class problems, along with the scoring rubric, and having them score the results. This was followed by a comparison of the scores and a discussion of why each participant scored the problem in the manner that they did. A second round of scoring, was then performed during the workshop.

Results to Date

To date, only a preliminary analysis of the attitudinal survey results has been completed as reported at last year's ASEE Annual Meeting and Exposition ${ }^{19}$. This is briefly recapped below.

\section{Attitudinal Data}

\section{Within Year Analysis}

For each academic term, a within-year analysis was conducted to determine whether students' opinions changed across time and if there were any main effects based upon other factors (Gender, Race, and Major).

Among the factors showing significant changes, Task Value (e.g., "I think I will be able to use what I learn in this course in other courses”) scores decreased significantly. In addition, Critical Thinking (e.g., "I treat the course material as a starting point and try to develop my own ideas about it”) scores increased for Chemical Engineering students while Bioengineering students' 
scores decreased. Finally, Classroom Connectedness (e.g., "I feel connected to others in this course") scores decreased if students were female Chemical Engineering majors, but increased if they were a female Bioengineering major. In contrast, males' Classroom Connectedness scores increased regardless of whether they were a Chemical Engineering major or a Bioengineering major.

\section{Combined Year Analysis}

Given the differences that were observed for each scale in the within year analyses, we examined whether these effects would also be observed if all three years were examined simultaneously. Again, the results were mixed and often contingent upon the demographic variable and its interactions with the assessments. Collapsing across all three years of data, it was found that Task Value scores decreased significantly. The Self-Efficacy scores were found to differ as a function of both Race and Major. Analyses of students' Critical Thinking scores yielded a significant interaction with Gender. Women's Critical Thinking scores decreased whereas men's scores increased. Similar results were found with Peer Learning: females' scores decreased whereas males' scores increased.

\section{Summary}

Although both the within year and combined year analyses showed changes, only for half of the scales was the Pre-Post factor found to interact with Year and, therefore, with exposure to SBL (Task Value, Mastery Goal Orientation, Classroom Connectedness, Classroom Learning, as well as Persistence). This suggests that for the other scales (i.e., Self-Efficacy, Critical Thinking, Peer Learning, and Intrinsic Goal Orientation), the patterns remained relatively stable across years. Again, the stability across years indicates that there were no changes resulting from the use of SBL.

The combined year analyses revealed only one main effect (Task Value), but the within year analyses revealed main effects in several instances (e.g., Classroom Connectedness in 2011, Task Value and Intrinsic Goal Orientation in 2012, and Task Value in 2013). This suggests that the most stable impact of the studio-based learning environment is the impact it has on students' views of Task Value. Unfortunately, the stable impact of the new instructional technique yielded a decrease in students' perceptions of the class' Task Value. However, even Task Value scores were found to vary as a function of Major, Race, and Gender. This suggests that these Task Value scores, as well as those from other scales, must be evaluated in light of the demographic characteristics of the students who provide those scores.

\section{Qualitative Data}

As part of the overall research for this project, all participants were asked to complete a series of 50 qualitative questions. The questions were either "yes/no" questions or open-ended questions related to specific aspects of the course. The qualitative questions can be sub-divided into the following areas:

- Expectations

- Impact on learning through specific experiences

- Interest in chemical engineering 
- Social interaction

- Confidence and comfort in receiving and providing feedback

Out of the five "themes" listed above, only two showed qualitatively focused themes related to the research of this project.

Social Interaction. Across all three years, the students seemed to grow in the social interaction domain. There were many students who referred to themselves as "extroverts" and stated that the course had little impact on their social interactions. However, there were some notable statements from students who considered themselves to be "introverts". They admitted that the course forced them to become more social. It is interesting that this happened in all three years, including the traditional year. For 2011, it was noted that the social interaction was based upon an interdependence developed through study groups. For 2012 and 2013, while the study groups did continue, many of the students noted that they were forced to communicate with other classmates more often due to the SBL process. However, the 2013 cohort mentioned that it preferred "face-to-face" opportunities to the online interactions. Yet, many of the students understood and appreciated the online interactions.

Confidence and comfort in receiving and providing feedback. The most notable differences in responses were found in this domain. For 2011, the students expressed that they had limited opportunities to provide and receive feedback from their peers. During 2012 and 2013, the student's attitudes changed drastically. Due to being forced to provide and receive feedback from classmates, the students overwhelmingly stated that their confidence and comfort in receiving and providing feedback increased. While they missed the face-to-face interactions with their classmates on the problems (and the discussions connected to them), they stated that being forced to exchange feedback had many positive aspects. Most notably, a few students noted that it "helped me feel better about myself because I saw that it was challenging to everyone else." Many noted that the online environment was "basically just a study group online".

\section{Knowledge Gain}

We recently began a preliminary analysis of the results from the pre-/post-class traditional material/energy balance problems assigned to students at this university. As mentioned above, a scoring rubric was developed for both the traditional and the critiquing problems to insure uniformity of scoring across institutions and years. The rubric for the "traditional" problem broke down the scoring of each student's problem solution into three areas: Diagram Components, Stream Components, and Equations. The maximum number of points possible in each category varied, depending upon the difficulty level of the problem. Since the class at Washington State Univesity covers both material and energy balances, the maximum number of points in the three categories above are 10, 46, and 14, respectively.

The Diagram Components category focused on whether a student could properly identify the number and type of processing units in a process flow diagram and connect them in the proper order. The Stream Components category focused on whether a student could properly describe the amount (or flow rate) and composition of each stream in the process flow diagram. This included a full description of known quantities (including identifying all components in the stream, their flow rate or compositions, and consistent and correct units) as well as identifying 
unknown quantities. For unknown quantities in any stream, students were required to identify components in the stream and provide proper units; they were required to indicate the amount of each component (or total stream flow) as an unknown. The Equations category focused on whether the students could derive enough, independent equations (either from material/energy balances, specifications within the problem statement, or other sources) to solve for all of the unknowns in the problem. Finally a Total score was given by weighting each of the three categories above by $0.2,0.3$ and 0.5 , respectively.

The scoring rubric for the critiquing problem was simpler. The critiquing problem given to the students at Washington State University was a combined material and energy balance problem containing nine imbedded errors. Students were also given a blank table. For each error, students were asked to indicate where the error occurred (process flow diagram or equation), what the error was, and how the error could be corrected. The scoring was either a 0 or a 1 depending upon whether the student's response was incorrect (or missing) or correct, respectively. Thus a maximum score of 27 (9 errors $\times 3$ points/error) was possible on the critiquing problem.

The same traditional and critiquing problems were given to students during the $2011-2012$ (traditional classroom conduct) and the 2012 - 2013 and 2013 - 2014 (SBL) academic years. As expected, the student scores were higher on the problems given at the end of the semester than at the start, so the difference between the end-of-semester scores and the start-of-semester scores was positive. The table below gives a summary of the results for the three academic years considered in our study.

Table 1: Comparison of Usual versus SBL Score Changes

\begin{tabular}{|l|c|c|c|}
\hline & $2011-2012$ & $2012-2013$ & $2013-2014$ \\
\hline Diagram Component & 1.7 & 1.2 & 1.8 \\
\hline Stream Component & 13.4 & 13.8 & 17.2 \\
\hline Equation & 7.8 & 7.7 & 7.6 \\
\hline Total & 8.3 & 8.2 & 9.3 \\
\hline Critiquing & 2.7 & 1.2 & 2.6 \\
\hline
\end{tabular}

Comparing the results from 2011 - 2012 (Control Treatment) versus those from 2012 - 2013 and 2013 - 2014 (Experimental Treatments) shows no significant change in student learning as assessed by improvements in solving problems.

\section{Retention}

Another factor that can be assessed is the impact of the SBL approach on student success/retention in the material/energy balance class at Washington State Univesity. Shown in the figure below is the retention data in the material/energy balance class at this university over the past 20 years. Retention, in this case, means that a student received a grade of “ $C$ ” or higher in the material/energy balance class, a requirement in order to enroll in any higher level class in the discipline. The instructor involved in this project (RZ) started teaching the material/energy balance class in 2007. Prior to that the average percentage of students enrolled in the class who did not achieve a $\mathrm{C}$ or higher in the class was $36 \%$. The average perentage of students taking the class from this instructor who did not receive a $\mathrm{C}$ or higher prior to the implementation of the 
SBL approach is $26 \%$, while after implementing the SBL approach this percentage dropped to $19 \%$.

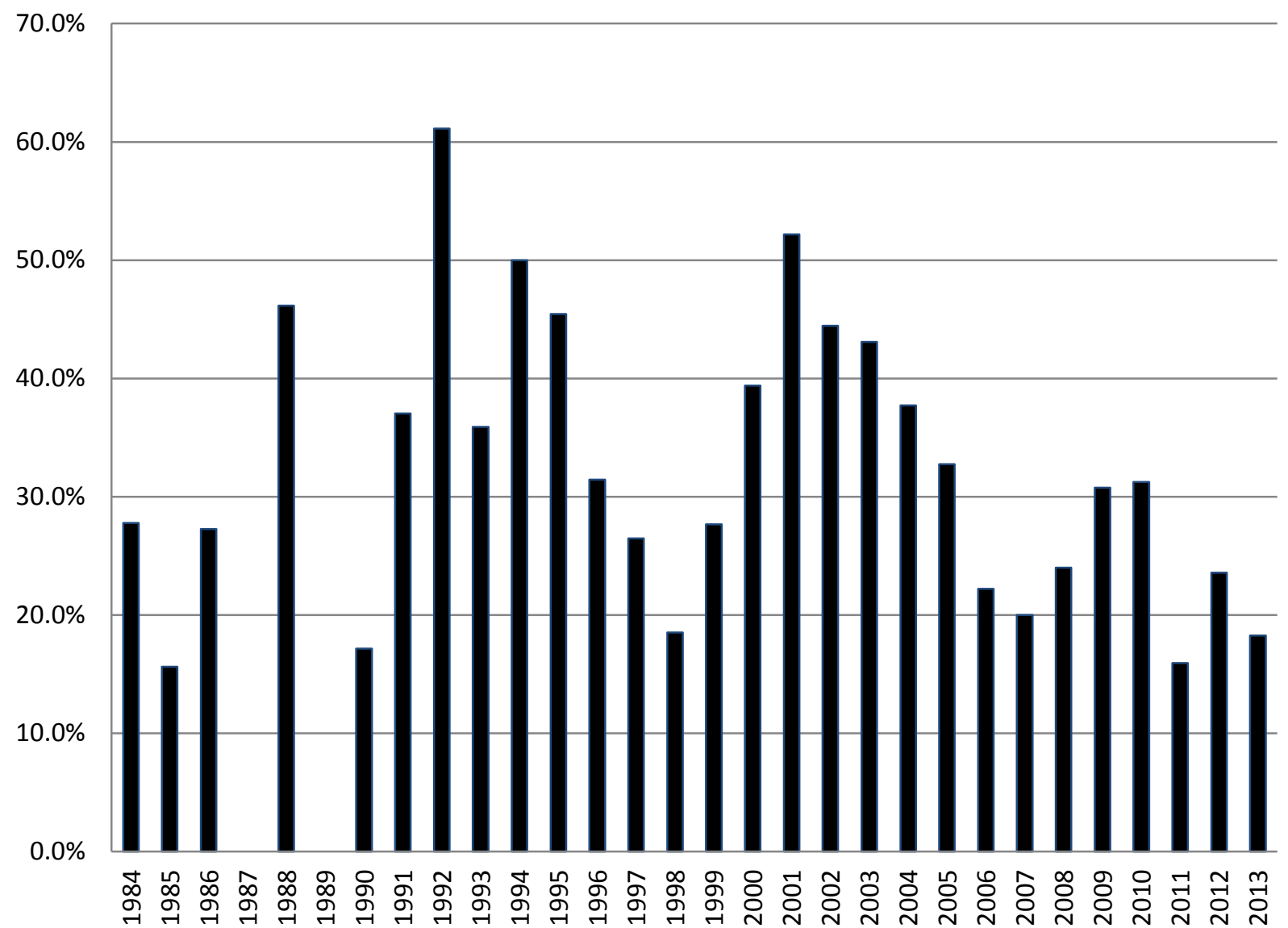

Figure 3: Percentage of Students receiving less than a C

\section{Additional Data}

During the 2014 - 2015 academic year, the lead author split the duties of teaching the material/energy balance class with another faculty member at Washington State University. Both sections of the class followed the same schedule, gave common tests and quizzes, and were graded on a common basis. The only difference between the sections, other than the instructors, was the manner in which the classroom sessions were handled. This instructor continued to use a variety of active classroom techniques, including SBL, while the other instructor used a more traditional lecture/work problems technique. No attempt was made to randomize students in the two sections; it was assumed that the size of the two sections (47 and 41) would insure that the average ability of the students in both sections was equal. The average grade $(\mathrm{A}=4.00)$ on the quizzes and tests, along with the final grade in the course, in the two sections are shown below.

Inspection of Table 2 suggests that students in Section 1 (taught by the first author) received slightly higher grades on the exams/quizzes in the class. At the conclusion of the class the average grade for the students in Section 1 was a B-, compared to a C+ for the students in Section 2. More importantly the percentage of students failing to receive a $\mathrm{C}$ or higher in 
Table 2: Grade Comparison between Sections

\begin{tabular}{|l|c|c|}
\hline & Section 1 & Section 2 \\
\hline Quiz Grade & 2.8 & 2.8 \\
\hline Hour Exam Grade & 2.3 & 2.2 \\
\hline Final Grade & 2.8 & 2.4 \\
\hline Course Grade & 2.5 & 2.2 \\
\hline
\end{tabular}

Section 1 was $17 \%$ versus $29 \%$ in Section 2 . Because the students in both sections took the same quizzes and tests, and the grading was equally shared between both of the instructors, these differences can be attributed to the manner in which the two classes were taught.

Data from the other institutions participating in this study are currently being analyzed. Since the instructors at these other institutions use a variety of teaching styles any impact of the SBL approach might become clearer with the analysis of all of the data.

Since SBL techniques require that students use all levels of Bloom's taxonomy, there should be an observable increase in judgment type activities among the students. We have seen this on an anecdotal basis in the two years using SBL at Washington State University. Because the critiquing portion of the SBL activity was conducted on-line, we have a complete transcript of all discussions that took place. We have developed a rubric to analyze these transcripts to assess whether students are demonstrating the higher-level skills in Bloom's taxonomy. The transcripts are currently being assessed to determine if the development of higher level learning skills can be quantified.

\section{Conclusion}

Studio Based Learning (SBL) offers many advantages for student instruction. In addition to being an active learning technique, the construct-present-critique-respond cycle within SBL addresses all six cognitive levels of Bloom's taxonomy. An impediment to the integration of SBL into a typical class is the time constraint imposed by the usual one-hour long time block for most classes. We have combined two software programs (ChemProV and OSBLE) to overcome this difficulty. Preliminary analysis of data from our institution indicates mixed to negligible positive results for the impact of SBL on the student's knowledge and attitude in the material/energy balance class. Retention data from our institution indicate that the percentage of students not making satisfactory progress in the material/energy balance class has dropped to half its prior value after implementing the SBL approach.

A confounding factor in the data from this institution is the fact that the first author (RZ) has implemented a number of active learning techniques in the material/energy balance class prior to the implementation of the SBL approach. Comparing results from the most recent offering of the material/energy balance class would indicate that using an active learning technique, with SBL being one such approach, has a stronger effect on student learning and retention than the implementation of any single active learning technique. 


\section{Literature Cited}

1 L. Anderson, A taxonomy for learning, teaching, and assessing: a revision of Bloom's taxonomy of educational objectives, New York, Longman

2 E. L. Boyer and L. D. Mitgang, Building Community: A New Future for Architecture Education and Practice, Princeton, NJ, The Carnegie Foundation for the Advancement of Teaching, 1996.

3 J. Lave and E. Wenger, Situated Learning: Legitimate Peripheral Participation, New York, Cambridge University Press, 1991.

4 C.D. Hundhausen, N.H. Narayanan, and M.E. Crosby, "Exploring Studio-Based Instructional Models for Computing Education,” Proc. 2008 ACM Symposium on Computer Science Education, 392, New York, ACM Press.

5 M. Oliver-Hoyo and R Beichner, "The SCALE-UP Project," Teaching and Learning through Inquiry: A Guidebook for Institutions and Instructors,” edited by V. S. Lee, Stylus Publishing, Sterling, VA, 2004.

M. Koretsky, K. J. Williamson, J. A. Nason, G. Jovanovic, C-H. Chang, A. Z. Higgins, C. M. Gates, R. M. Roehner, “Using Studios as a Strategy to Respond to Increasing Enrollment," Proc. ASEE Annual Conference and Exposition, June 10 - 13, 2012.

$7 \quad$ M. Prince, Journal of Engineering Education, 93(3), 223 (2004).

8 B. S. Bloom, M. D. Engelhart, E. J. Furst, W. H. Hill, and D. R. Krathwohl, Taxonomy of Educational Objectives: The Classification of Educational Goals; Handbook I: Cognitive Domain, New York, Longmans, Green, 1956.

$9 \quad$ R. L. Zollars, C. D. Hundhausen, and M. Stefik, "Visual Learning in a Material/Energy Balance Class,” Proc. ASEE Annual Conference and Exposition, June 24 - 27, 2007.

10 R.M. Felder and L.K. Silverman, “Learning and Teaching Styles in Engineering Education”, Engr. Education, 78(7), 674 (1988).

11 L. S. Vygotsky, Mind in Society, Harvard University Press, Cambridge, MA (1978).

12 C. Quintana, B. Reiser, E. Davis, J. Krajcik, E. Fretz, R.G. Duncan, E. Kyza, D. Edelson, and E. Soloway, “A Scaffolding Design Framework for Software to Support Science Inquiry”, Journal of the Learning Sciences, 13, 337 (2004).

13 M. Guzdial, "Software-Realized Scaffolding to Facilitate Programming for Science Learning”, Interactive Learning Environments, 4, 1 (1994).

14 A. Bandura, "Self-Efficacy: Toward a Unifying Theory of Behavioral Change”, Psychological Review, 84, 191 (1977).

15 C. Hundhausen, P. Agrawal, R. L. Zollars, and A. Carter, “The Design and Experimental Evaluation of a Scaffolded Software Environment to Improve Engineering Students' Disciplinary Problem-Solving Skills”, Journal of Engineering Education, 100(3), 574, (2011).

16 C.D. Hundhausen, A. Agrawal, and K. Ryan, "The Design of an Online Environment to Support Pedagogical Code Reviews”, Proc. 2010 ACM Symposium on Computer Science Education, 182, New York, ACM Press.

17 P. R. Pintrich, D. A. F. Smith, T. Garcia, and W. J. Mckeachie, "Reliability and Predictive Validity of the Motivated Strategies for Learning Questionnaire (Mslq)”, Educational and Psychological Measurement, 53(3), 801 (1993).

18 A. P. Rovai, "Development of an Instrument to Measure Classroom Community”, Internet and Higher Education , 5(3), 197 (2002).

19 R. L. Zollars, C. Hundhausen, D. Smith, and A. Carter, "Studio-based Learning in Multiple Material/Energy Balance Classes”, Proc. ASEE Annual Conference and Exposition, June 15 - 18, 2014 